
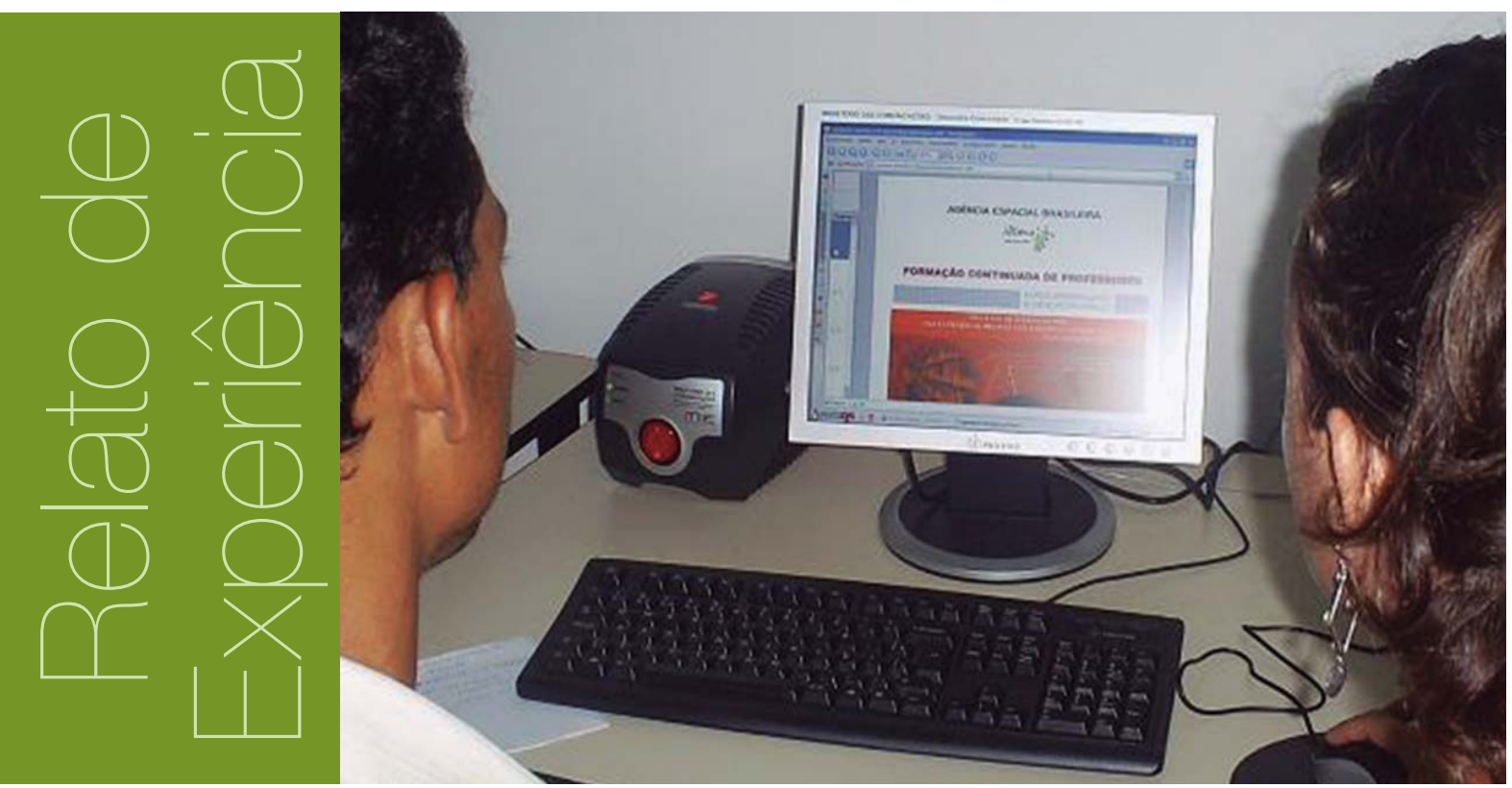

\title{
Formação continuada para professores em metodologias educativas e tecnologias digitais
}

Tiago Dziekaniak Figueiredo - tiago@furg.br

\section{RESUMO}

0 texto apresenta 0 trabalho desenvolvido com 12 professores da educação básica do município de Vila Propício, Goiás, que participaram do curso de formação ministrado pela equipe do Projeto Rondon da Universidade Federal do Rio Grande - FURG, na Operação Centro-Norte, em janeiro de 2009, sobre a utilização de metodologias de ensino combinado com 0 uso pedagógico das tecnologias digitais.

\section{PALAVRAS-CHAVE}

Tecnologias digitais. Metodologias de ensino. Ferramentas pedagógicas. Formação de professores.

\section{ABSTRACT}

The text presents the work with 12 teachers of basic education in the municipality of Vila Propicio / GO who participated in the training course taught by the Rondon Project team from the Federal University of Rio Grande - FURG in Operation North Central in January 2009 on the use of teaching methods combined with the pedagogical use of digital technologies.

\section{KEYWORDS}

Digital technologies. Teaching methodologies. Teaching tools. teachers training.

1 Doutorando em Educação - UFPEL; Mestre em Educação em Ciências e Licenciado em Matemática - FURG. 


\section{Relato de experiência}

\subsection{Justificativa}

Os perceptíveis avanços tecnológicos de que a sociedade ao longo dos anos vêm se beneficiando levam-nos a repensar os espaços educacionais e a formação de professores como mediadores na construção de ambientes que favoreçam as aprendizagens para a vivência com o coletivo. Neste sentido, acreditamos que a inserção de novas metodologias de ensino- como a metodologia de projetos de aprendizagem, que, imbricadas ao uso pedagógico das tecnologias digitais, são capazes de contribuir na formação dos sujeitos envolvidos.

A situação de projeto de aprendizagem pode favorecer especialmente a aprendizagem de cooperação, com trocas recíprocas e respeito mútuo. Isto quer dizer que a prioridade não é o conteúdo em si, formal e descontextualizado. A proposta é aprender conteúdos, por meios que desenvolvam a própria capacidade de continuar aprendendo, num processo construtivo e simultâneo de questionar-se, encontrar certezas e reconstruí-las em novas certezas. Isto quer dizer: formular problemas, encontrar soluções que suportem a formulação de novos e mais complexos (FAGUNDES et al. 2001, p. 21).

Nesta perspectiva, desenvolvemos um trabalho com professores da educação básica do município de Vila Propício, Goiás, que participaram do curso de formação continuada para professores intitulado "A metodologia de projetos de aprendizagem: uma nova visão para educadores do século XXI", curso este que integrou as ações extensionistas desenvolvidas pela equipe do Projeto Rondon da Universidade Federal do Rio Grande-FURG, na Operação Centronorte, em janeiro de 2009.

0 curso teve por objetivo capacitar os docentes da educação básica daquele município para o trabalho com metodologias de ensino inovadoras, articulado ao uso pedagógico das tecnologias digitais. 0 curso foi executado em três etapas que compreenderam: a apresentação de projetos bem-sucedidos desenvolvidos pela universidade e que seguem a mesma linha, como, por exemplo, o Projeto "Escola-Comunidade-Universidade: buscando metodologias educativas, interativas e interconectivas em uma visão sistêmica - ESCUNA"; o diálogo sobre os pressupostos teóricos da metodologia de projetos de aprendizagem; e as formas de inserção das tecnologias digitais no fazer pedagógico de cada professor.

É importante ressaltar que o Município de Vila Propício situa-se no estado de Goiás, na microrregião chamada de Entorno de Brasília, possui uma área de 2.181,575 km² e uma população estimada em 5.282 habitantes, dos quais aproximadamente 1,5 mil vivem na sede do município. 0 restante da população mora no Distrito de Assunção de Goiás e na zona rural. Vale ainda, salientar que na zona rural do município existem cinco assentamentos de trabalhadores rurais, o que contribui para evidenciar a demanda por professores capacitados para lidar com diferentes situações, contextos e necessidades.

\subsection{Metodologia}

Nas três etapas, o curso beneficiou 12 professores: sete da rede municipal e cinco da rede estadual de ensino, que foram convidados a (re)pensar suas práticas educativas e a desenvolver em sala de aula trabalhos inovadores, fundamentados metodologicamente e potencializados pelos recursos tecnológicos. Além disso, a atividade propiciou aos acadêmicos da FURG a possibilidade de compartilhar seus saberes e conhecer, de uma forma não linear, outras formas do fazer pedagógico, bem como, oportunidades de conhecer e de explorarem diferentes ambientes de ensino e aprendizagem.

No primeiro encontro do curso, foi feita uma apresentação da metodologia, com dados oriundos de projetos de pesquisa e de informações cedidas por professores de escolas participantes do Projeto ESCUNA e pela coordenadora do Núcleo de Tecnologia Educacional - NTE, bem como uma exploração inicial do livro digital "Aprendizes do Futuro: as inovações começaram" (Figura 1). 
No segundo dia, foi feito o desencadeamento dos projetos de aprendizagem com os professores, por meio da utilização de jornais, revistas, etc., na tentativa de mostrar que o trabalho pode ser iniciado a partir dos mais diferentes recursos, através do levantamento de assuntos do interesse dos alunos, para que então os conteúdos curriculares possam ser explorados. No último encontro foi elaborada coletivamente uma rede de conteúdos interdisciplinares que poderiam ser trabalhados nos projetos desenvolvidos pelos professores.

Figura 1: Professores explorando o livro.

Fonte: 0 autor.

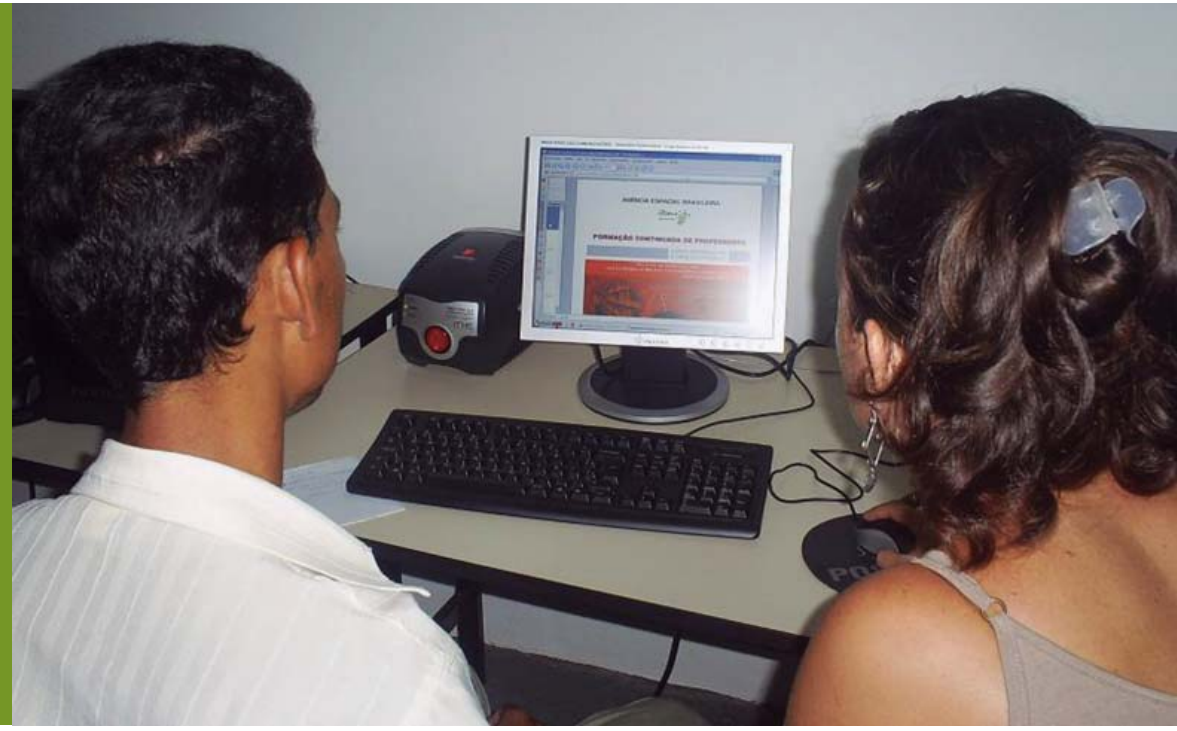

Como atividade de encerramento, foi realizada uma teleconferência com uma das autoras do livro explorado durante o primeiro dia de atividades (Figura 2), que foi adotado como referencial teórico do curso, a fim de gerar o debate acerca do uso da metodologia proposta. Este livro foi distribuído às participantes do curso, em meio digital (CD-ROM), com a intenção de ser usado como fonte futura para o desenvolvimento dos projetos.

Figura 2: Videoconferência. Fonte: 0 autor.

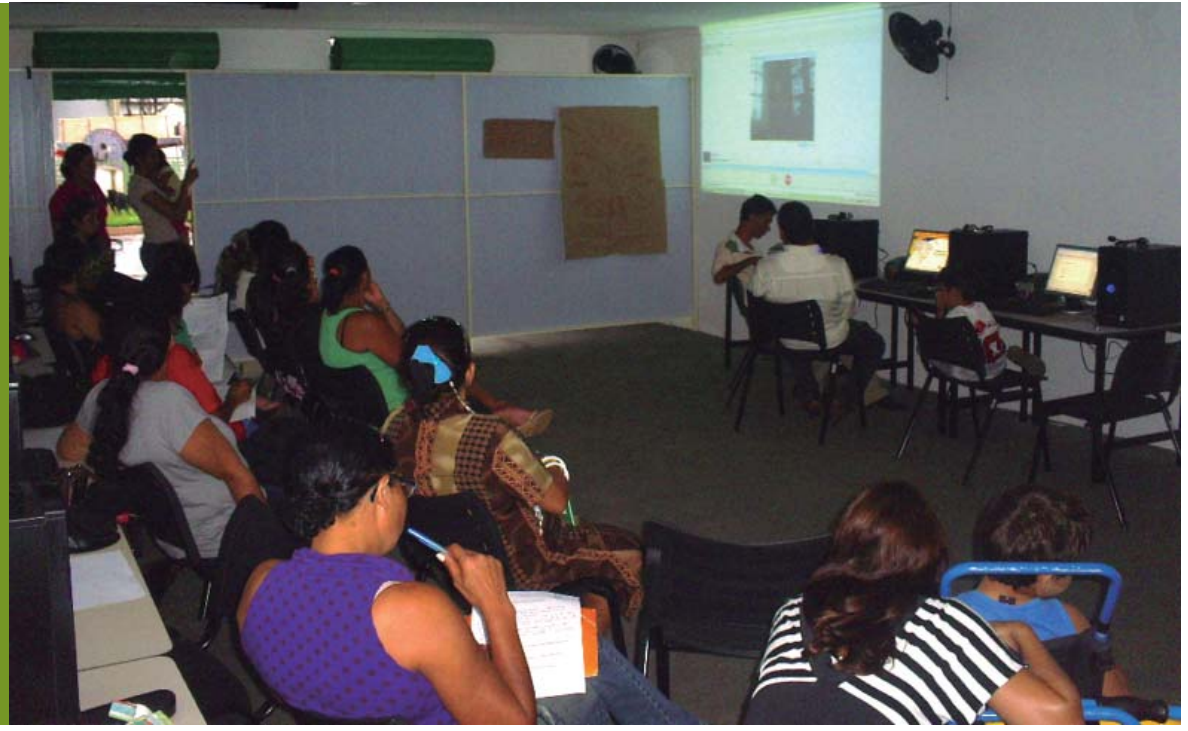

\subsection{Resultados}

A abordagem metodológica utilizada através da metodologia de projetos de aprendizagem (FAGUNDES et al. 2001) foi adotada por compreendermos que os projetos são desenvolvidos através do levantamento das certezas sempre provisórias e das dúvidas temporárias dos estudantes, o que favorece o envolvimento de cada aluno em seu processo de ensinoaprendizagem através da busca de respostas para suas dúvidas. Com isto, os questionamentos, 
mesmo não relacionando diretamente os conteúdos escolares, em sua grande maioria podem ser utilizados como uma forma de contextualização mais abrangente e significativa na vida de cada sujeito e trabalhados de forma interdisciplinar; e, por envolverem o cotidiano de cada aluno, tornam-se atrativos, despertando 0 interesse dos mesmos (FAGUNDES et al. 2001).

Assim como afirma Figueiredo, ao utilizar a metodologia de projetos de aprendizagem,

[...] as dúvidas que surgem dos próprios alunos são por eles respondidas, consequentemente reformuladas e passíveis de novamente serem sanadas. Por meio do trabalho com projetos de aprendizagem, as dúvidas motivam o aprender e não se calam a partir do momento em que são respondidas (FIGUEIREDO, 2015, p. 63).

Com a utilização desta metodologia, a sala de aula passa a ser mais um dos inúmeros espaços de construção de conhecimentos, não mais sendo o único e exclusivo lugar, pois o aluno, ao questionar-se sobre suas dúvidas, cria a vontade de saná-las e seguir em busca de seu aprendizado, percebendo seu cotidiano como uma preciosa fonte de conhecimentos.

A educação acontece em todas as partes: na rua, no colégio, em casa, na comunidade a que se pertence. E é uma aprendizagem e educação que tem uma dimensão do que aquela que aparece explícita na declaração educativa: é por isso que o que se aprende é um modo de viver (MATURANA, 1993, p. 64).

Usar as tecnologias digitais é essencial para que a metodologia de projetos de aprendizagem desfaça as barreiras e ultrapasse os limites das salas de aula e, principalmente, o limite das escolas, pois por meio do uso delas, ou seja, com o computador ligado à Internet, por exemplo, será possível a interação simultânea, através de salas de bate-papo, ou não-simultâneas, como os ambientes virtuais de aprendizagem, que possibilitarão trocas recíprocas de conhecimento entre os mais diversos e distantes alunos e professores.

É importante ressaltar que inserir as tecnologias digitais no ambiente da escola não significa apenas ter acesso às tecnologias, mas saber utilizá-las com o objetivo de encontrar materiais que permitam aos alunos e professores resolverem problemas do cotidiano, compreendendo 0 mundo e atuando na transformação do seu entorno.

\subsection{Considerações finais}

0 curso de formação continuada para professores gerou muitas inquietações quanto ao fazer pedagógico de cada professor, servindo, possivelmente, como objeto desencadeador de práticas pedagógicas inovadoras e fazendo-os compreender o seu papel no mundo atual, no qual devem comprometer-se na formação de sujeitos aptos a viverem no século XXI.

No curso, os professores familiarizaram-se com novas formas de ensinar, potencializadas pelo uso das tecnologias digitais, encontrando também na metodologia de projetos de aprendizagem uma boa oportunidade para estreitar os laços entre a escola e a comunidade, (re)configurando seus saberes e fazeres, explorando os diversos contextos em que seus alunos estão inseridos.

Na metodologia, alunos e professores assumirão o compromisso com a pesquisa ao estabelecer uma estreita relação entre a aprendizagem que acontece na escola e na vida. Viver esta experiência nos faz compreender a multiplicidade de saberes que se engendram no coletivo e que são capazes de mobilizar uma outra prática docente, na qual o compartilhamento de ideias e propostas pautadas pelo coletivo irão redefini-las.

Como professores, necessitamos nos respaldar de metodologias capazes de motivar nossos alunos para construírem seu conhecimento e, neste sentido, destacamos o uso da metodologia de projetos de aprendizagem como uma possibilidade nesta construção, uma vez que esta metodologia possibilita uma construção coletiva e que pode ser pautada no contexto social e cultural dos envolvidos, promovendo a valorização do conhecimento prévio de cada sujeito.

Por fim, cabe destacar que cursos de formação continuada de professores no âmbito da extensão universitária tem contribuído para a melhoria da qualidade do ensino nas escolas. Ações como a relatada neste trabalho articularam ensino, pesquisa e extensão, o que foi fundamental para atingirmos nossos objetivos junto aos professores de Vila Propício, Goiás. 


\section{Referências}

FAGUNDES, Léa da Cruz; SATO, Michele.; LAURINO, Débora Pereira. Aprendizes do futuro: as inovações começaram. Brasília: PROINFO/SEED/MEC, 2001.

FIGUEIRED0, Tiago Dziekaniak. Os professores de matemática e as tecnologias digitais: uma cultura docente em ação. 2015. 91p. Dissertação (Mestrado) - Programa de PósGraduação em Educação em Ciências: Química da Vida e Saúde, Universidade Federal do Rio Grande - FURG, Rio Grande, 2015.

MATURANA, Humberto. Uma nova concepção de aprendizagem. Dois pontos, v. 2, n. 15, 1993). 